however, for the production of the book. It makes slow and often uninteresting reading despite tho exciting subject matter. Perhaps someone ought to read the article by the Editor of Nature, "Is the Literature Dead or Alive?"

M. H. L'. BotT

\section{QUANTUM MECHANICS}

The Mathematical Principles of Quantum Mechanics By Derek F. Lawden. Pp.xiv + 280. (London : Mothuen and (o., Ltd., 1967.) 50s. net.

DuRINe the past twenty years or so, a scarcity of books on quantum mechanies has been happily transformod into a situation whore thore now exists an embarrassingly wide selection of good books on this fundamental subject, so that the need for new books has eonsiderably diminished unless they possoss some original feature.

As its title suggests, the volume under review sets out to emphasize the mathematical aspects of quantum mochanics whilo mostly disregarding the physics of the subject. The book begins with a chapter on the representation of states by vectors in a multi-dimensional voctor space. Thon comos a chapter on spin operators followed by chapters on operators possessing continuous eigenvalue spectra, on the variation of state vectors with time, on angular momentum operators, on perturbation theory and on Dirac's relativistic theory of the electron.

The presentation of the subject matter is quito straightforward. The operator approach to quantum mechanies is chosen as the basis of the subject and the Schrödinger equation arises in the developmont as tho eigenvalue oquation for tho Hamiltonian operator in the co-ordinate representation. Regrettably there is virtually no discussion of the relationship between the Schrödinger equation and classical mechanics: my belief is that this connexion is an extremely important one, for it leads to considerable clarification of the position of quantum mechanies in the genoral fiold of physics, and indeed was the original approach used by Schrödinger.

This book by Lawson also omits discussion of variational principles and mothods, and it only takes a cursory glance at the theory of collisions as an application of perturbation theory. Nevertheless it can be recommended to a student whose primary interest is in the mathematical aspects of quantum mechanics, for it presents a lot of valuable material very clearly, but for a fuller understanding of the subjoct it would need to be supplemented by other books.

B. L. Morseiwitsoh

\section{NEW ASPECTS OF REPRODUCTION}

\section{Advances in Reproductive Physiology}

Vol. 2. Edited by Anne McLaren. Pp. 347. (London: Logos Press, Ltd., in association with Elok Books, I.td., 1967. Distributed by Academic Press, New York and London.) $75 \mathrm{~s}$.

IT can be argued with some justification that thcre are already too many books on fertility and reproduction. Certainly, there is a wealth of review on the subject and it is depressing, not to say painful, to compare the volume of relevant literature with its substance. As a discipline, the biology of reproduction seems to be sorely in need of a major breakthrough, and a constant flow of monographs, in which authors repeatedly ask tho same questions instead of getting on with answering them and saying something new, can be extremely tedious. Moreover, thero is always tho danger that tho "multiple author" type of book merely serves as a platform for certain individuals to parade as experts in their field. A book intended to bo purposeful can thus be marred. Such judgments should, of course, be tempered by the fact that monographs involve an enormous amount of difficult work, and if they are done properly they should be and are of interest and great value.

Anne McLaren clearly has a flair for editing, for she avoids almost all the best known pitfalls. It is claimed in the editor's foreword that the volume is " . . . noither balaneed or integrated", and it would seem largely because of this that the book is by no means a run of the mill text on reproduction.

Tho first two chapters are about behaviour. This alone makes the book "different" and is an advance on volume 1 which covered more conventional topies. The first chapter" of volume 2, by Margarot Bastock, is particularly effective in that it contains a nice attempt to integrate behaviour and physiological mechunisms, and although in the second chapter M. P. M. Richards does not try to do this, he succeeds in making maternal behaviour in rodents and lagomorphs a fascinating subject.

A. B. Gilbert writes the third chapter on egg formation in the chicken. This is a novel and absorbing part of the book and its inclusion is most refreshing. Lightheartedly, however, I cannot resist mention of the banality of the opening sentence in this chapter which is only outshone by the opening phrase of the noxt chapter. Chapter 4 is written by B. J. Restall and is an attempt to survey the biochemical and physiological relationships between the gametes and the female reproductive tract. To try to do this in twenty pages is to attempt the impos. sible and, needless to say, the impossible has not been achieved. Nevertheless, the twelve pages of references are a useful supplement to a brave if superficial approach to the problem.

Chapters 5 and 6 , respectively, on oostrogens and implantation, are erudite, but less appropriate to this volume than most of the other chapters. This in no way reflects on such distinguished authors as Professors Emmens and Psychoyos; indeed, chapter 5 is probably the best written chapter in the whole book. But the subjects are too topical to be in context. Could it also be that in these two chapters much is assumed for the uninitiated, and little new is added for the expert? It will be for each sort of reader to make a personal decision on this.

A chapter by Peter Gruenwald on growth in the human foetus is a valuable contribution, and the closing chapter by J. M. Tanner on puberty is scholarly and affords some intriguing information, even though it is perhaps a bit light on purely physiological aspects of tho problem.

This book should have wide appeal, and it can certainly be recommended to reproductive physiologists and other biologists, not because it is just another book on reproduction, but because it is an unusual and informative book on reproduction. The title of the book bears hardly any relation to its contents, but this is of little import here, and if anything it enhances the interest.

\section{T. D. Glover}

\section{Appointments}

Rear-Admirar F. Dossor has been appointed director of hovercraft at the Ministry of Technology.

Dr R. B. BuzzarD, at present research director of the National Institute of Industrial Psychology, has been appointed director of the institute in succossion to Dr C. B. Frisby.

\section{Announcements}

C. H. VAN DE HULST, profossor of theoretical astronomy at Leiden, has been elected to succeed Dr A. Hocker as chairman of the council of ESRO for 1968; Professor R. Lüst, director of the Max-Planck-Institut für Extraterrestrische Forschung, Munich, and chairman of the Launching Programmes Advisory Committee of ESRO, and Dr J. Stiernstedt, head of the Department of 